\title{
Structural, Optical and Electrical Properties of Copper Doped Alkali Borate Glasses
}

Srinivas G ( $\nabla$ srinu123g@gmail.com )

Osmania University

\section{Boora Srinivas}

VNR Vignana Jyothi Institute of Engineering and Technology

D. Komaraiah

Osmania University

\section{Md. Shareefuddin}

Osmania University

\section{R. Sayanna}

Osmania University

\section{Raj Kumar Samudrala}

National Institute of Technology Warangal

\section{Research Article}

Keywords: Borate glasses, XRD, UV-VIS, FTIR, and Electrical properties, mixed alkali effect

Posted Date: October 20th, 2021

DOl: https://doi.org/10.21203/rs.3.rs-988680/v1

License: (c) (1) This work is licensed under a Creative Commons Attribution 4.0 International License.

Read Full License 


\title{
Structural, optical and electrical properties of copper doped alkali borate glasses
}

\author{
G. Srinivas ${ }^{\mathrm{a}}$, B. Srinivas ${ }^{\mathrm{b}}$, D. Komaraiah ${ }^{\mathrm{a}}$, Md. Shareefuddin ${ }^{\mathrm{a}}$ R. Sayanna ${ }^{\mathrm{a}}$ and Raj Kumar Samudrala ${ }^{\mathrm{c}}$ \\ a Department of Physics, Osmania University, Hyderabad-500007, Telangana state, India. \\ ${ }^{b}$ Department of Physics, VNR Vignana Jyothi Institute of Engineering and Technology, Hyderabad-500090, \\ Telangana, India \\ ${ }^{c}$ Department of Physics, National Institute of Technology Warangal, Telangana, India \\ * Corresponding author email Id: srinu123g@gmail.com
}

\section{Abstract}

The compositional effect on Physical properties, Optical absorption and Electrical properties of glass composition $\mathrm{xK}_{2} \mathrm{O}-(25-\mathrm{x}) \mathrm{Li}_{2} \mathrm{O}-12.5 \mathrm{BaO}-12.5 \mathrm{MgO}-49 \mathrm{~B}_{2} \mathrm{O}_{3}-1 \mathrm{CuO}(\mathrm{x}=0,5,10,15,20$ and $25 \mathrm{~mol} \%$ ) was prepared by the melt-quenching technique. From optical absorption spectra few parameters, like Urbach energy, indirect allowed, reflection loss (R), refractive index (n), molar polarizability $\left(\alpha_{m}\right)$, molar refractivity $\left(\mathrm{R}_{\mathrm{m}}\right)$, and theoretical optical basicity $\left(\Lambda_{t h}\right)$ values of prepared glass samples were measured. The values of $\mathrm{R}_{\mathrm{m}}, \alpha_{m}$, and $\Lambda_{t h}$ were increase with increasing of x mol\%. The $\mathrm{E}_{\mathrm{opt}}, \mathrm{R}$, and $\mathrm{n}$ values were changed very small with $\mathrm{x}$ mol\%, which may be due to the nonbridging oxygen's moments in the glass matrix. The FTIR spectrum of prepared borate glasses indicates that the influence of $\mathrm{BO}_{3}$ and $\mathrm{BO}_{4}$ units of boron atoms. The explicit vibrational peaks were exhibited of $\mathrm{Li}-\mathrm{O}, \mathrm{K}-\mathrm{O}, \mathrm{Mg}-\mathrm{O}$, and $\mathrm{Ba}-\mathrm{O}$ bonds in glass network, and A.C conductivity study was devised to know the structural information about the glass network. The drastic change in the ionic conductivity as a function of the alkali content in the glass composition was analyzed by considering both the ionic mobility and the glass structure. Some physical, optical, and electrical values varied non-linearly with the $\mathrm{K}_{2} \mathrm{O}$ content, which may influence of non- bridging oxygens or mixed alkali effect. 
Keywords: Borate glasses, XRD, UV-VIS, FTIR, and Electrical properties and mixed alkali effect;

\section{Introduction}

The glass is divided into main categories, network formers, network modifiers and transition metal ion species, which falls somewhere between glass modifiers and network formers. Glass modifiers may substitute in a network former and then change the glass structure and glassy state. Generally, Glasses are amorphous materials, it has been used in different fields like optical, electrical and potential devices and building glass materials. For the glass products, manufacturings, thermal conductivity and solid-state lithium-ion batteries around room temperature [1]. The chemical composition of the glasses plays an important role in determining the properties of the glass. The transition metal ions have more than one valence state in the outermost shell, they show semiconductor properties such as switching, electro-chromatic, fuel cells, solid-state lithium-ion batteries and chemical sensors application [2-5].In the mixed alkali borate glasses, the glass modifiers are alkali oxides $\left(\mathrm{Li}_{2} \mathrm{O}\right.$ and $\left.\mathrm{K}_{2} \mathrm{O}\right)$ and glass farmer is borate oxide $\left(\mathrm{B}_{2} \mathrm{O}_{3}\right)$. The $\mathrm{BO}_{3}$ units can be converted to $\mathrm{BO}_{4}$ units with creating bridging oxygen by the addition of glass modifiers in the glass network borate oxide $\left(\mathrm{B}_{2} \mathrm{O}_{3}\right)$. And vice-versa $\mathrm{BO}_{4}$ units also could be transforming into $\mathrm{BO}_{3}$ units and oxygen dangling bonds are produced. This type of phenomena is called non- bridging oxygens (NBOS) effect [6], it occurs in mixed alkali borate glasses (MAE).

In borate mixed alkali oxide glasses if total alkali content constant is kept constant, when two types of alkali oxide are introduced in borate glass former, in which one alkali ion is gradually replaced by another alkali ion, the exhibited non-linear behaviour in some physical properties or breaking the oxygen bonds in B-O or the glass network variation of non- bridging oxygens (NBOS)

effect observed. This effect is also known as the mixed alkali effect (MAE) [7]. The ratio between $\frac{\mathrm{BO}_{3}}{\mathrm{BO}_{4}}$ gives the structural changes, which controls and exhibits non-linear variation values in physical 
electrical Properties such as density, molar volume, energy band gap, electrical conductivity, ionic diffusion, and dielectric relaxation, etc parameters of mixed alkali borate glasses. Most of the research work on MAE is based on the physical properties of the glasses. However, the influence of MAE is not considerably studied in like Optical absorption, FTIR and Electrical properties. Some research workers studied the MAE in the spectroscopic and electrical properties of glasses [8-15]. The glasses contain alkali ions and substitute transition metal oxides make colored glasses, these are generally acting as optically colorless and ionic conductors. Ultimately these glass modifications lead to the size-dependent structural, optical and electronic properties, these glasses can be designed to be suitable for energy storage and electrical device applications by varying the alkali oxides in the glass host material.

In the present research work, we have studied and analyzed the correlation between the pure and copper doped mixed alkali borate glasses and also, we focus on ionic conductivity studies of copper doped alkali borate glass systems. MAE investigates the non-linear variation in some of the physical, spectroscopic like UV-VIS, FTIR and electrical properties of alkali copper doped borate glasses.

\section{Experimental Method}

The current alkali oxide borate glass samples were mixing required amounts of potassium carbonate $\left(\mathrm{K}_{2} \mathrm{CO}_{3}\right)$, lithium oxide $\left(\mathrm{Li}_{2} \mathrm{O}\right)$, magnesium oxide $(\mathrm{MgO})$, and barium oxide $(\mathrm{BaO})$ with boric acid $\left(\mathrm{H}_{3} \mathrm{BO}_{3}\right)$. The current compositions were accommodated as a host and doped with copper oxide $(\mathrm{CuO})$ ions host materials were reported in Table 1 . The present glass preparation and X-ray diffractograms were recorded as explained in detail. The influence of the optical absorption spectra of present glass samples was investigated [13].

At room temperature, the reported FTIR spectra of the present glass system were recorded with 
a heap of Perkin Elmer Frontier FTIR. In this technique, KBr pallet and sample ratio 2:100 was used to record the FTIR spectra with an applied pressure of 7-8 ton using a hydraulic press. The KBr pallet background removal and baseline correction were observed by using Spectrum 10 software.

For electrical measurements, the silver past was coated on two sides of polished glass samples that were used to study electrical properties. The silver coated glass samples were free heat-treated upto $150^{\circ} \mathrm{C}$ for electrode stabilization. The Impedance, capacitance, and admittance parameters were recorded from Impedance analyzer with an applied frequency range from $100 \mathrm{~Hz}$ to $1 \mathrm{MHz}$ and temperature variation from 523 to $673 \mathrm{~K}$ by using a low-frequency impedance analyzer (AUTO LAB PGSTAT). A. C conductivity temperature-dependent at low temperatures and varies strongly at high temperatures and real part of impedance $Z(\vartheta)$ is studied as a function of frequencies with different temperatures. At high temperatures, tends to reach the value of DC conductivity and shows activated temperature dependence for all alkali copper doped borate glasses.

\section{Results and Discussion}

\subsection{XRD}

All the prepared glass samples of the XRD (Pan Analytic) pattern show the absence of sharp Bragg's free peak to confirmed homogeneous and amorphous nature. Fig.1 shows the XRD pattern of all prepared glass samples at room temperature.

\subsection{Density and molar volume}

At room temperature, the density value was measured by using Archimedes' principle with xylene $(99.99 \%)$ for all the prepared glasses [16]. The density values were evaluated three times for error elimination. Subsequently, the molar volume values were evaluated from density values. The molar volume mostly associated with the spatial distribution alkali oxygen's in the glass matrix. Density and molar volume provides a relationship between masses and the volume of different types 
of structural oxide groups inside the borate glass matrix and key factors to study the physical properties of alkali borate host materials. Similarly, the molar volume can be describing the glass network structure and arrangement of the building units as it deals with the spatial structure of the oxygen network. The small change in the density and molar volume values such as around $2.75 \mathrm{~g} / \mathrm{cc} \&$ $26.765 \mathrm{cc} / \mathrm{mol}$, but $2.812 \mathrm{~g} / \mathrm{cc}$ is highest density value for $\mathrm{Li}_{2} \mathrm{O}$ content and $2.744 \mathrm{~g} / \mathrm{cc}$ is low-density value for $\mathrm{K}_{2} \mathrm{O}$ content and molar volume values increases with the $\mathrm{K}_{2} \mathrm{O}$ content in the alkali borate host materials. The measured values of density and molar volume values were given in Table-2. Fig.2 plots show the variation of $\rho$ and $\mathrm{V}_{\mathrm{m}}$ as a function of $\mathrm{K}_{2} \mathrm{O}$ content, which manifests the mixed alkali effect and it's maybe also noted that ionic radius of alkali modifiers in the present glass system $[17,18]$.

\subsection{Optical basicity}

The theoretical optical basicity $\left(\Lambda_{t h}\right)$ of all the glass samples values were evaluated by using the following equation [18]

$$
\Lambda_{t h}=\mathrm{x}_{2} \mathrm{O} \Lambda_{K_{2} \mathrm{O}}+\mathrm{xLi}_{2} O \Lambda_{L i_{2} \mathrm{O}}+\mathrm{xMgO} \Lambda_{\mathrm{MgO}}+\mathrm{xBaO} \Lambda_{\mathrm{BaO}}+\mathrm{xB}_{2} \mathrm{O}_{3} \Lambda_{B_{2} O_{3}}+\times \mathrm{CuO}_{\text {CuO }}
$$

Here the alkali oxide theoretical optical basicity value taken and explained about theoretical values [16]. The copper oxide theoretical optical basicity value is taken from [19]. The mixed alkali borate glass system of theoretical optical basicity $\left(\Lambda_{t h}\right)$ values are increased with a decrease of the Pauling electronegativity of the modifiers also increasing fromLi $\mathrm{i}_{2} \mathrm{O} \rightarrow \mathrm{Na}_{2} \mathrm{O} \rightarrow \mathrm{K}_{2} \mathrm{O}$ content, these values are reported in Table 2 . The theoretical optical basicity $\left(\Lambda_{t h}\right)$ values are increases with increasing $\mathrm{K}_{2} \mathrm{O}$ content in the alkali borate host materials, it was suggested that the local states (coordination and valence) of transition metal ions in the glass matrix and finally the glass makes color itself.

\subsection{UV-Vis absorption spectra}


Fig.3 shows the optical absorption spectra of $\mathrm{xK}_{2} \mathrm{O}-(25-\mathrm{x}) \mathrm{Li}_{2} \mathrm{O}-12.5 \mathrm{BaO}-12.5 \mathrm{MgO}-$ $49 \mathrm{~B}_{2} \mathrm{O}_{3}-1 \mathrm{CuO}(\mathrm{x}=0,5,10,15,20$ and $25 \mathrm{~mol} \%)$ glass system. The optical absorption spectra of the present glass system influence of copper oxide glasses give broad absorption bands explained 13] and are shown in fig.3.From the $\mathrm{UV}-\mathrm{Vis}$ absorption spectra of $\mathrm{Cu}^{2+}$ ions having a broad absorption band positions at a different wavelength and is reported in Table.2. A broad absorption band was investigated at $700 \mathrm{~nm}(\mathrm{x}=0 \mathrm{~mol} \%)$ and $733 \mathrm{~nm}(\mathrm{x}=25 \mathrm{~mol} \%)$ for corresponding to $\mathrm{Li}_{2} \mathrm{O}$ and $\mathrm{K}_{2} \mathrm{O}$ content, remaining absorption bands were varied non-linearly, which manifest the non- bridging oxygens (NBOS) and MAE in present alkali oxides glass samples. From the optical absorption spectra, indirect optical energy gaps $\left(\mathrm{E}_{\mathrm{opt}}\right)$ were allowed transitions are shown in Fig.4. The present glass samples of $E_{\text {opt }}$ determined values were reported in Table.2. Fig.5 shows the plots drawn between the $\ln$ $(\alpha)$ Vs photon energy $h \vartheta$ and exhibits the Urbach energy values of present mixed alkali borate glass samples are presented in Table.2. At $\mathrm{X}=0,3.241 \mathrm{eV}$ and $0.220 \mathrm{eV}$ are the values of bandgap energy and Urbach energy for $\mathrm{Li}_{2} \mathrm{O}$ content, these values are very small and more applications compared to $\mathrm{Na}_{2} \mathrm{O}$ $\& \mathrm{~K}_{2} \mathrm{O}$ contents. For $\mathrm{K}_{2} \mathrm{O}$ content $($ at $\mathrm{X}=25$ ) the bandgap energy and Urbach energy values are $3.285 \mathrm{eV} \& 0.287 \mathrm{eV}$ respectively, above values are similarly matching with A. Bhogi[20]. The nonlinear variation of bandgap and Urbach energy values are shown in Fig.6, which manifests the mixed alkali effect and non-bridging oxygens of the present glass system.

\subsection{Refractive index (n) \& Dielectric constant (\&)}

Refractive index and dielectric constant values are the most powerful important parameters related to glass structure modification. The refractive index and dielectric constant values of mixed alkali-alkaline earth oxides borate glass samples containing $\mathrm{Cu}^{2+}$ ions were calculated from optical band gap energy using eq. and explained details [2] and are reported in Table.2.From the Table.2dielectric constant and refractive index values are higher for $\mathrm{Li}_{2} \mathrm{O}$ content and smaller for $\mathrm{Na}_{2} \mathrm{O}$ 
\& $\mathrm{K}_{2} \mathrm{O}$ contents, but remaining values were varied non-linearly in the present glass samples, which can be due to the mixed alkali effect (MAE) in the borate glass material. High refractive index material can have higher density and lower bandgap energy [21]. This may be expected due to its structure of glass and chemical composition of alkali oxides in the borate network.

\subsection{Reflection loss $(\mathbf{R})$, Molar refraction $\left(\mathbf{R}_{\mathrm{m}}\right)$ and Molar polarizability $\left(\alpha_{\mathrm{m}}\right)$}

The values of Reflection loss can be calculated from refract index values and Molar refraction and Molar polarizability values evaluated from molar volume and refract index. The reflection loss $(\mathrm{R})$ values of the present glass system can be calculated from the refractive index of glasses by using the Fresnel's formula [6,16 and 22].

$$
R=\left(\frac{n-1}{n+1}\right)^{2}
$$

The Reflection loss values varies non-linearly with increasing $\mathrm{K}_{2} \mathrm{O}$ content and with small variation could be due to the NBO in glass host materials. Molar refraction and Molar polarizability are useful physical parameters to find glass structure and its defects in the glass network. Molar refraction values will be evaluated by using the Lorentz-Lorenz equations [23- 25]

$$
R_{m}=\left[\frac{\left(n^{2}-1\right)}{\left(n^{2}+2\right)}\right] v_{m}
$$

Where $\mathrm{n}$ is the refractive index and $\mathrm{V}_{\mathrm{m}}$ is the molar volume of the present glass system,

The molar polarizability $\left(\alpha_{m}\right)$ as a function of molar refraction can be calculated for each glass samples using relation

$R_{m}=2.52 \alpha_{m}$

The evaluated values of present glasses of molar refraction and molar polarizability were reported in Table.2. The $R_{m}$ and $\alpha_{m}$ values increase with the increase of $\mathrm{K}_{2} \mathrm{O}$ content mol\%. Therefore the increase in molar volume, Theoretical optical basicity and Broad Optical absorption band with an 
increase of $\mathrm{K}_{2} \mathrm{O}$ content, these suggested that this will be due to transition metal ions of local states or NBO in the glass matrix.metallization is defined from the Herzfeld theory, it means the metallization is the ratio of $\frac{R_{m}}{v_{m}}$ is called polarizability per unit volume[26], based on metallization ( M ) condition criteria, it is $M=1-\frac{R_{m}}{v_{m}}$. The materials act as metallic nature, if only $\frac{R_{m}}{v_{m}}>1$ and the materials act as insulator nature if only $\frac{R_{m}}{v_{m}}<1$ for an expectation of prepared present glass samples are acting as an insulator[27]. Small changes in the metallization values were observed. These metallization criterion values are given in Table 2. The metallization nature is more for $\mathrm{Li}_{2} \mathrm{O}$ content compared to $\mathrm{K}_{2} \mathrm{O}$ content, i.e metal oxides radius is increased metallization is decreased. Copper doped metallization values decrease compared to pure borate glass systems, which means that the width of both valence and conduction bands become closer, resulting in a decrease of bandgap and an increase of the metallic nature of the glass.Fig.7 influence the variation of refractive index and metallization as a role of molar polarizability, the non-linear variation suggest that which may be due to the NBO or MAE. Some researchers are showing MAE in physical and spectroscopic studies[20, 28-30].

\subsection{FTIR spectra}

The influence of active FTIR spectra recorded at room temperature with wavenumber range $400^{-1}$ to $1600 \mathrm{~cm}^{-1}$. Fig. 8 suggested the FT-IR transition spectra of mixed alkali oxide borate glass of glass-forming structural units for quality identification in glass materials; it can be explained in detail [2]. TheFT-IR transition spectrum can be divided into 3 parts in which one at $400-800 \mathrm{~cm}^{-1}$ range of wavenumber is due vibrations of alkali \& alkaline earth cations moments, the second one in the wavenumber range $800-1200 \mathrm{~cm}^{-1}$ are due to tetrahedral $\mathrm{BO}_{4}$ units of $\mathrm{B}-\mathrm{O}$ asymmetric stretching and from FTIR spectra another band at about $1200-1600 \mathrm{~cm}^{-1}$ corresponding to the stretching relaxation of borate units in $\mathrm{BO}_{3}$ units $[6,10,12,20$ and31,32]. The sharp, deep and brand transition bands were reported in Table.3. In the present article, we discussed sharp, deep bands at $416 \& 462 \mathrm{~cm}^{-1}$ are due to 
$\mathrm{Li}_{2} \mathrm{O}$ content and deep band $430 \mathrm{~cm}^{-1}$ is due to $\mathrm{K}_{2} \mathrm{O}$ content. The bands around $718 \mathrm{~cm}^{-1}$ and $1026 \mathrm{~cm}^{-1}$ are suggested that the coordination of $\mathrm{BO}_{3}$ units can be shifted toBO $\mathrm{O}_{4}$ units with the creation of NBO in the glass network is identified. The deep active strong bands $707 \mathrm{~cm}^{-1}$ and $723 \mathrm{~cm}^{-1}$ corresponding to $\mathrm{Li}_{2} \mathrm{O}$ and $\mathrm{K}_{2} \mathrm{O}$ contents respectively, which may be due to symmetrical stretching vibrations of $\mathrm{B}-\mathrm{O}-\mathrm{B}$ linkages in $\mathrm{BO}_{3}$ units. The bands position at $1354 \mathrm{~cm}^{-1} \& 1400 \mathrm{~cm}^{-1}$ and $1207 \mathrm{~cm}^{-1} \& 1387 \mathrm{~cm}^{-1}$ are attributed to stretching vibrations of $\mathrm{Li}-\mathrm{O}-\mathrm{B}, \mathrm{K}-\mathrm{O}-\mathrm{B}$ linkages and $\mathrm{B}-\mathrm{O}-\mathrm{Basymmetric}$ and symmetric vibrations in $\mathrm{BO}_{3}$ units. Furthermore, additional transition peaks appeared at higher wavenumber region, $1598 \mathrm{~cm}^{-1}, 1600 \mathrm{~cm}^{-1}, 1410 \mathrm{~cm}^{-1}$ and $1412 \mathrm{~cm}^{-1}$ are generated due to the creation of NBO in glass host materials. And also FTIR spectra the wavenumber range from $400 \mathrm{~cm}^{-1}$ to $500 \mathrm{~cm}^{-1}$ is assigned to the bending vibrations of various borate segments and the presence of various specific vibrations of K$\mathrm{O}, \mathrm{Na}-\mathrm{O}, \mathrm{Mg}-\mathrm{O}$ and $\mathrm{Ba}-\mathrm{O}$, which is also due to bending modes of $\mathrm{Cu}-\mathrm{O}$ bonds [20,32-34].

\subsection{Electrical studies}

A.C conductivity study is the most important and powerful technique to study the electrical and impedance properties of glass materials. Electrical studies give the conductivity nature of host material and investigation of conductivity belongs to the motion of charged particles. The appearance of conductivity will be a reasonable response of activated hopping manner of mobile charges, therefore it can occur moment of mass and charge in the material. Fig. 9, show the variation in impedance $\left(Z^{\prime}\right)$ with frequency at different temperatures for present glass system composition $\mathrm{xK}_{2} \mathrm{O}$ - (25-x) $\mathrm{Li}_{2} \mathrm{O}-12.5 \mathrm{BaO}-12.5 \mathrm{MgO}-49 \mathrm{~B}_{2} \mathrm{O}_{3}-1 \mathrm{CuO}$. From the figures, it was observed that $Z^{\prime}$ decrease with an increase in frequency at all temperatures, which indicates the decrease of the resistive property of all the glass samples. From these figures, it is clear that the values of $Z^{\prime}$ are found to decrease with an increase in frequency up to $10 \mathrm{k} \mathrm{Hz}$ then after becomes constant with further increase in frequency. This may be due to rapid polarization processes occurring in all the glass at low frequency (below 10K 
$\mathrm{Hz}$ ). These types of investigation can be possibly due to the decrease of space charge in the material of impedance pattern. All the curves are merging with one another at higher frequencies (above $10 \mathrm{~K} \mathrm{~Hz}$ ) [35]. The measured values of $Z^{\prime}$ are reported in Table. 4 at $100 \mathrm{~Hz}, 1 \mathrm{~K} \mathrm{~Hz}, 100 \mathrm{~K} \mathrm{~Hz}$ and at $300^{\circ} \mathrm{C}$ temperature for mixed alkali oxide borate glass samples. It is found that impedance decrease with an increase in the value of frequency. At higher temperature, the energy distribution in the glass network become more uniform and the variation of the magnitude of impedance values at higher frequencies become very less. This indicates that the impedances to converge at higher frequencies and also reveals that at higher frequencies conductivity and impedance become independent of temperature.

A.C conductivity study was devised to know the structural information about glass network.A.C conductivity is the dependence frequency is used to study the characterization of convenient formalism to investigate in a material with help of power-law relation proposed by Jonscher [36].

$$
\sigma_{T}(\omega)=\sigma_{o}+A \omega^{s}
$$

where $\sigma_{T}$ is total conductivity, $\sigma_{o}$ is frequency independence (dc) conductivity, the coefficient $\mathrm{A}$ and exponents are corresponding temperatures and material-dependent parameters respectively. The $A \omega^{S}$ term indicates comprises the ac conductivity and characterization of all dispersion phenomena [37-39]. In a material the exponents can vary with corresponding temperature and more variation with material to another material,i.e., $0 \leq \mathrm{s} \leq 1$. Fig. 10shows the frequency-dependent conductivity plots with a variation of frequency from $100 \mathrm{~Hz}-1 \mathrm{MHz}$ at different temperatures (from $250-400^{\circ} \mathrm{C}$ ) for the present glass system. The ac conductivity of present glass systems shows similar frequency dependence. From fig. 9 we suggest that the at low-frequency range ac conductivity is almost constant, then after abruptly increases in the high-frequency region.It is concluded that the electrical conduction mechanism is the same as that process of the dielectric polarization in the low-frequency region. 
Present all the glass samples show the conductivity as increasing trend with increasing temperature. The conductivity increases may attribute to a number of bridging oxygen increase in atoms and mobile charge carriers in the glass matrix. The observed conductivity spectra can be divided into two distinct regions. The first dispersive region at high-frequency range (above $10 \mathrm{~K} \mathrm{~Hz}$ ) manifests the back-and-forth motion of the ions. The second dispersive region at low-frequency range (below $10 \mathrm{~K} \mathrm{~Hz}$ ) due to the long-range transportation, it signifying the D.C conductivity.

At the same frequency, the temperature is increasing, at which the conductivity becomes prominently transform to higher frequencies or high conductivity due to space charge polarization [40, 41]. At high-frequency regions, increasing the kinetic energy of the ions and as well as vibrational frequency increases. In the low-frequency region accumulation of space charge carrier or mobile ion effect due to the electrode, polarization was observed at two different temperatures. Therefore finally, we conclude that the frequency decreased as the total conductivity of all the glasses decreases at constant temperature, and conductivity increases as the temperature increases for all the glass materials. The recorded electrical/ionic conductivity values at different frequencies with temperature variation weregiven in Table.5 for KLMBBC glass systems. FromTable.5it was observed that the ionic conductivity increases with an increase in temperature and at a higher temperature $\left(400^{\circ} \mathrm{C}\right)$ the mobile ions are more active and low resistivity in alkali oxide borate glass network. The conductivity also depends on the density and ionic radius of alkali oxides. Mixed alkali borate glasses act as semiconductors at higher temperatures. High conductivity for $\mathrm{Li}_{2} \mathrm{O}$ compared to another alkali oxide, may be used for battery application [38]. The similar electrical results are reported for alkali ions conducting glasses used for different applications [42]. In amorphous material at low-frequency region enhancement of AC conductivity may be due to the interfacial or space charge polarization and it also disorder distribution of relaxation time occurs [43]. The conductivity values decrease with increasing 
ionic radius from $\mathrm{Li}^{+}$to $\mathrm{K}^{+}$ions, due to the increase of non-bridging oxygen atoms. Thus suggesting that the conductivity values were related to the density, glass transition temperature and band gaps. Fig. 11 shows the variation of $\sigma_{a c}$ versus $10^{3} / \mathrm{T}$ at $10 \mathrm{k} \mathrm{Hz}$ frequency for present glass systems. It is observed that the conductivity of glasses increases with the increase in temperature according to the Arrhenius relation [44].

$$
\sigma_{a c}=\sigma_{0} \exp \left[-\frac{\Delta E}{k T}\right]
$$

where $\Delta E$ is the activation energy for the $\mathrm{AC}$ conduction mechanism, "k" is the Boltzmann constant, $\mathrm{T}$ is the temperature and $\sigma_{0}$ is the pre-exponential factor. From the investigated present glass system, it is found that the slope variation was high at a higher temperature, which indicates that at higher temperature region samples show high conductivity and also having less activation energy.

From the graphs a careful observation recorded, the curves separated into two characteristic regions point of deviation from a straight line, from which activation energy values were evaluated. At lower temperature regions the activation energies are tabulated in Table 6. The activation energy is associated with the hopping of ionic reorientation within the glasses. At low temperatures generally, the dominancy of electronic conductivity is present in all the glass samples. Hence, here conductivity decreases and activation energy increases, they show the opposite behavior in all prepared glass material. The decrease in conductivity is further supported by an increase in density and a decrease in molar volume with the addition of different alkali content. The increase in density and decrease in molar volume, which1 suggests the rigidity of glass structure and network formalism. The activation energy of ionic conduction $\left(E_{\text {ac }}\right)$ values was calculated from the slope of $\sigma_{a c}$ versus $10^{3} /$ Tfor each glass sample and the calculated values are presented in Table 6. Fig. 10 gives a negative slope indicates that ionic conductivity in these samples is satisfied by the theory of the electronic structure of amorphous materials. Variation in the electrical resistivity with temperature by several orders of magnitude was 
observed [45]. It is proposed to discuss the changes in activation energy with the changes in the molar ratio of modifiers. This model assumes that the ion transport is considered to be "site preferred" which takes place by hopping from one site to another rather than the migration through specific pathways. The mobility of the ions is considered to be essentially dependent on the mechanism of the hopping process and overall glass composition [46].

\section{Conclusions}

Resultants of the XRD pattern of the prepared glasses are given the absence of sharp peaks to confirm the amorphous nature. The density of glass samples has generally been used to get qualitative information about the compactness of structure when changing the composition. The bandgap, molar polarizability and Urbach energy values increase while density, refractive index and oxygen packing density values decreasing from $\mathrm{Li}^{+}$to $\mathrm{K}^{+}$ions, It was found that increase of the concentration of nonbridging oxygen atoms with an increasing alkali contents radii.

FT- IR spectra of the KLMBBC glass system the sharp, deep bands at around $400 \mathrm{~cm}^{-1}$ and 700 $\mathrm{cm}^{-1}$ peaks are spread and shifted to the higher energy side corresponding to the $\mathrm{Li}_{2} \mathrm{O}$ and $\mathrm{K}_{2} \mathrm{O}$, which indicates that increase non-bridging oxygen atoms (NBO's) and decrease glass network connectivity of Li-O-B and K-O-B linkages. The bands around $1015 \mathrm{~cm}^{-1}$ and $986 \mathrm{~cm}^{-1}$ peaks are spread and shifting towards lower energy side corresponding to $\mathrm{Li}_{2} \mathrm{O}$ and $\mathrm{K}_{2} \mathrm{O}$ contents respectively, which indicates that increase asymmetric stretching vibrations of borate segments and also intensity and amplitude with the addition of alkali modifiers in the borate network.

The impedance values increase with an increase of ionic radius from $\mathrm{Li}^{+}$to $\mathrm{K}^{+}$ions, which contribute to increasing non-bridging of oxygen atoms while the impedance decrease with increasing frequency. The addition of alkali oxides to the borate network to form bridging and non-bridging oxygen atoms can also be attributed to the mixed mobile ion effect. The high-frequency dispersion of 
the conductivity is due to the microscopic nature of inhomogeneity in the glasses with the distribution of the relaxation process through the distribution of energy barriers. At $400^{\circ} \mathrm{C}$ for alkali oxides like $\mathrm{Li}_{2} \mathrm{O}, \mathrm{Na}_{2} \mathrm{O}$ and $\mathrm{K}_{2} \mathrm{O}$, the conductivity of glass samples show an increasing trend with the decreasing radius of alkali ion. The increase in conductivity may be due to an increase in the number of mobile charge carriers in addition to alkali contents to the borate glass matrix. Thus suggesting that the conductivity values were related to the density, glass transition temperature and band gaps. The conductivity values decrease with increasing ionic radius from $\mathrm{Li}^{+}$to $\mathrm{K}^{+}$ions, due to the increase of non-bridging oxygen atoms. The activation energy values vary non- linearly as a function of alkali contents, it suggests that the change of borate glass structures when the addition of alkali oxides acts as alkali modifiers in borate network. The activation energy for the ionic conduction could be changed from the $\mathrm{BO}_{3}$ into $\mathrm{BO}_{4}^{-}$structural units in the glass matrix. Finally, the values of physical, optical, magnetic and electrical properties like density, molar volume, molar polarization, refractive index, spin-Hamiltonian parameters, covalency rates, conductivity and activation energy, etc., are varying non- linearly as a function of alkali content, These variations are due to structural changes with changing alkali content which modify the boron network, leading to the increasing influence of NBOs. The non-linear behaviour may be due to the mixed alkali effect.

\section{Acknowledgments}

Authors thank CSIR (File No: 09/922(0008)/2019-EMR-I), New Delhi, India for the financial support. The authors thank Dr. G. Prasad, Head department of physics for providing electrical studies, G. Srinivas, thanks UGC DAE CSR, Indore center and Department of physics, Osmania University, Hyderabad, for providing research facilities.

\section{References}

1. Haruyuki Takahashi, Takeshi Karasawa, Takashi Sakuma, Jerzy E. Garbarczyk, Electrical 
conduction in the vitreous and crystallized $\mathrm{Li}_{2} \mathrm{O}-\mathrm{V}_{2} \mathrm{O}_{5}-\mathrm{P}_{2} \mathrm{O}_{5}$ system, Solid State Ionics 181 (2010) 27-32.

2. B. Srinivas, Abdul Hameed, G. Srinivas, M. Narasimha Chary, Md. Shareefuddin, Influence of $\mathrm{V}_{2} \mathrm{O}_{5}$ on physical and spectral (optical, EPR \& FTIR) studies of $\mathrm{SrO}-\mathrm{TeO}_{2}-\mathrm{TiO}_{2}-\mathrm{B}_{2} \mathrm{O}_{3}$ glasses, Optik, 225(2021) 165815

3. B. Srinivas, B. Srikantha Chary, Abdul Hameed, M. Narasimha Chary, and Md Shareefuddin. Influence of $\mathrm{BaO}$ on spectral studies of $\mathrm{Cr}_{2} \mathrm{O}_{3}$ doped titanium-boro-tellurite glasses, Optical Materials 109 (2020) 110329.

4. B. Srinivas, Abdul Hameed, G. Ramadevudu, M. Narasimha Chary, Md. Shareefuddin, Evaluation of EPR parameters for compressed and elongated local structures of $\mathrm{VO}^{2+}$ and $\mathrm{Cu}^{2+}$ spin probes in $\mathrm{BaO}-\mathrm{TeO}_{2}-\mathrm{B}_{2} \mathrm{O}_{3}$ glasses, Journal of Physics and Chemistry of Solids, 129 (2019) 22-30

5. R. Rajaramakrishna, ChatreeSaiyasombat, R.V. Anavekar, H. Jain, Structure and nonlinear optical studies of Au nanoparticles embedded in lead lanthanum borate glass, Journal of NonCrystalline Solids 406 (2014) 107-110.

6. F.A. Abdel-Wahab, A.M. Fayad, M. Abdel-Baki, HebaAbdelMaksoud, Role of non-bridging oxygen defect in the ionic conductivity and associated oxygen trap centers in lead-borate oxide glass: Effect of structural substitution of $\mathrm{PbO}$ for $\mathrm{Ag}_{2} \mathrm{O}$ and $\mathrm{Li}_{2} \mathrm{O}$ modifiers, Journal of NonCrystalline Solids 500 (2018) 84-91.

7. J.O.Isard, The mixed alkali effect in glass, J. Non- Cryst. Solids.1 (1969) 235.

8. R. P. S. Chakradhar, B.Yasoda, J. L. Rao, \& N.O. Gopal, Mixed alkali effect in $\mathrm{Li}_{2} \mathrm{O}-\mathrm{Na}_{2} \mathrm{O}-$ $\mathrm{B}_{2} \mathrm{O}_{3}$ glasses containing $\mathrm{CuO}$ - an EPR and optical study J. Non-Cryst. Solids 352 (2006) 3864. 
9. C.R. Kesavulu, R. P. S. Chakradhar, C.K. Jaya Sankar, \& J. L. Rao, EPR, optical, photoluminescence studies of $\mathrm{Cr}^{3+}$ ions in $\mathrm{Li}_{2} \mathrm{O}-\mathrm{Cs}_{2} \mathrm{O}-\mathrm{B}_{2} \mathrm{O}_{3}$ glasses-An evidence of mixed alkali effect, J. Mol. Struct., 975 (2010) 93.

10. M. Subhadra\& P. Kistaiah, Infrared and Raman spectroscopic studies of alkali bismuth borate lasses: Evidence of mixed alkali effect, Vibrational Spectroscopy, 62 (2012) 23-27.

11. Md. Shareefuddin, M. Jamal, G. Ramadevudu, M.L. Rao, \& M. Narasimha Chary, Electron paramagnetic resonance spectra of $\mathrm{VO}^{2+}$ ions in $\mathrm{NaI}-\mathrm{Na}_{2} \mathrm{O}-\mathrm{K}_{2} \mathrm{O}-\mathrm{B}_{2} \mathrm{O}_{3}$ mixed alkali glasses, J. Non-Cryst. Solids.255 (1999) 228.

12. V. Gajanan, Honnavar, K.P. Ramesh, \& S.V. Bhat, Role of Crystal Field in Mixed Alkali Metal Effect: Electron Paramagnetic Resonance Study of Mixed Alkali Metal Oxyfluoro Vanadate Glasses, J. Phy. Chem. A, 118 (2014) 573.

13. G. Srinivas,J. Siva Kumar, Md. Shareefuddin, M. N. Chary, and R. Sayanna, EPR and Optical Studies on Binary Mixed Alkali Alkaline Earth Oxide Borate Glasses Doped with $\mathrm{Cu}^{2+}$ Ions, J. Glass Physics and Chemistry, 42 (2016) 141-148.

14. M. Kim, H.W. Choi, C.H. Song, G.Y. Jin, Y.H. Rim, Y.S. Yang, Ionic conductivity in borate glasses with three types of mixed alkali cations, Solid State Ionics 180 (2009) 527-530.

15. W.C. Huang, H. Jain, G. Meitzner, The local structure of mixed alkali germanate glasses by EXAFS, Journal of Non-Crystalline Solids 255 (1999) 103-111.

16. G. Srinivas, B. Ramesh, J. Siva Kumar, Md. Shareefuddin, M.N. Chary, R. Sayanna, Mixed alkali effect in the physical and optical properties of $x \mathrm{~K}_{2} \mathrm{O}-(25-x) \mathrm{Na}_{2} \mathrm{O}-12.5 \mathrm{MgO}-12.5 \mathrm{BaO}-$ $50 \mathrm{~B}_{2} \mathrm{O}_{3}$ glasses, Journal of Taibah University for Science 10 (2016) 442-449.

17. Shashidhar Bale n, Syed Rahman, Studies of mixed former effect in EPR and optical absorption in xZnO-(75-x) $\mathrm{Bi}_{2} \mathrm{O}_{3}-15 \mathrm{~B}_{2} \mathrm{O}_{3}-10 \mathrm{Li}_{2} \mathrm{O}$ glasses, Physica B 418 (2013) 52-57. 
18. ArtiYadav, Manjeet S. Dahiya, A. Hooda, Prem Chand, S. Khasa, Structural influence of mixed transition metal ions on lithium bismuth borate glasses, Solid State Sciences 70 (2017) $54-65$.

19. A. Terczynska-Madej, K. Cholewa-Kowalska, M. Łaczka,Coordination and valence state of transition metal ions in alkali-borate glasses,Optical Materials 33 (2011) 1984-1988

20. Ashok Bhogi, R. Vijaya Kumar, P. Kistaiah, Effect of alkaline earths on spectroscopic and structural properties of $\mathrm{Cu}^{2+}$ ions-doped lithium borate glasses, Journal of Non-Crystalline Solids 426 (2015) 47-54.

21. Yannick Ledemi, Jean-Philippe Bérubé, RéalVallée, YounèsMessaddeq, Refractive index modification in fluoro-borate glasses containing $\mathrm{WO}_{3}$ induced by femtosecond laser, Journal of Non-Crystalline Solids 385 (2014) 153-159

22. B. Srinivas, Ashok Bhogi, Pallati Naresh, Abdul Hameed, M. Narasimha Chary, and Md Shareefuddin, Effect of $\mathrm{SrO}$ and $\mathrm{TeO}_{2}$ on the physical and spectral properties of strontium tellurite boro-titanate glasses doped with $\mathrm{Cu}^{2+}$ ions, Journal of Non-Crystalline Solids 575 (2022) 121218.

23. H.A. Lorentz, Ann. Phys., 9 (1880) 641.

24. L. Lorenz, Wiedem. Ann., 11(1881)70

25. J.A. Duffy, J. solid state chem..,62 (1986)145

26. A. Klinokowski, J. Non-Cryst. Solids 72 (1985) 117.

27. V. Sreenivasulu, G. Upender, V. Chandra Mouli, M. Prasad, Structural, thermal and optical properties of $\mathrm{TeO} 2-\mathrm{ZnO}-\mathrm{CdO}-\mathrm{BaO}$ glasses doped with $\mathrm{VO}^{2+}$,SpectrochimicaActa Part A: Molecular and Biomolecular Spectroscopy 148 (2015) 215-222. 
28. A.M. Abdelghany and Ahmed H. Hammad,SpectrochimicaActa Part A: Molecular and Biomolecular Spectroscopy,137 (2015) 39-44

29. T. RaghavendraRao, Ch. Rama Krishna, U.S. UdayachandranThampy, Ch. Venkata Reddy, Y.P. Reddy, P. SambasivaRao, R.V.S.S.N. Ravikumar, Physica B, 406 (2011) 2132-2137.

30. M.S. Dahiya, S. Khasa, A. Agarwal, Journal of Molecular Structure, 1086 (2015) 172-178.

31. R.S. Kundu, Sunil Dhankhar, R. Punia介, Kirti Nanda, N. Kishore, Bismuth modified physical, structural and optical properties of mid-IR transparent zinc boro-tellurite glasses, Journal of Alloys and Compounds 587 (2014) 66-73.

32. I. Kashif, A.A. Soliman, H. Farouk, M. El-Shorpagy, A.M. Sanad, Effect of copper addition on density and magnetic susceptibility of lithium borate glasses, Physica B 403 (2008) 39033906.

33. N. SrinivasaRao, Shashidhar Bale, M. Purnima, Ch. Srinivasu, M.A. Samee, K. Siva Kumar, Syed Rahman, Mixed alkali effect in $\mathrm{Cu}^{2+}$ doped boroarsenate glasses-EPR and optical absorption studies, Physica B 404 (2009) 1785-1789.

34. Yasser Saleh Mustafa Alajerami, SuhairulHashim, Wan MuhamadSaridan Wan Hassan, Ahmad TermiziRamli, The effect of $\mathrm{CuO}$ and $\mathrm{MgO}$ impurities on the optical properties of lithium potassium borate glass, Physica B 407 (2012) 2390-2397.

35. Ghada E. El-Falaky, Osiris W. Guirguis, Nadia S. Abd El-Aal, Progress in Natural Science: Materials International, 22 (2012) 86-93.

36. A. K. Jonscher, Dielectric Relaxation in solids, Chelsea Press, London, (1983) 214

37. Andrea Mogus-Milankovic, Kristina Sklepic, PetrMosner, LadislavKoudelka, and PetrKalenda, J. Phys. Chem. B, 120 (2016) 3978-3987.

38. S. K. Arya, S. S. Danewalia and K. Singh, J. Mater. Chem. C, 4 (2016) 3328-3336. 
39. H. Jain, H. L. Downing and N. L. Peterson, J. Non-Cryst. Solids, 64 (1984) 335.

40. J. Kawamura, M. Shimoji, J. Non-Cry. Solids, 79 (1986) 376-381.

41. P. H. Bottelberghs, solid electrolytes in: P. Hangenmuller, W. Van cool (Eds), Acadamic press, New York, (1978)

42. SajjanDahiya, R. Punia, S. Murugavel, A.S. Maan, Solid State Sciences, 55 (2016) 98-105.

43. A.E. Owen, J. M. Robenston, J. Non-Cry. Solids, 2 (1970) 347-357.

44. I. Kashif, Samy A. Rahman, A.A. Soliman, E.M. Ibrahim, E.K. Abdel-Khalek, A.G. Mostafa, A.M. Sanad, Physica B, 404 (2009) 3842-3849.

45. A. R. Kulkarni, P. Lunkenheimer, A. Loidl, Materials Chemistry and Physics, 63 (2000) 9397.

46. J. O. Isard, J. Non- Cryst. Solids, 1 (1969) 235. 
Figures

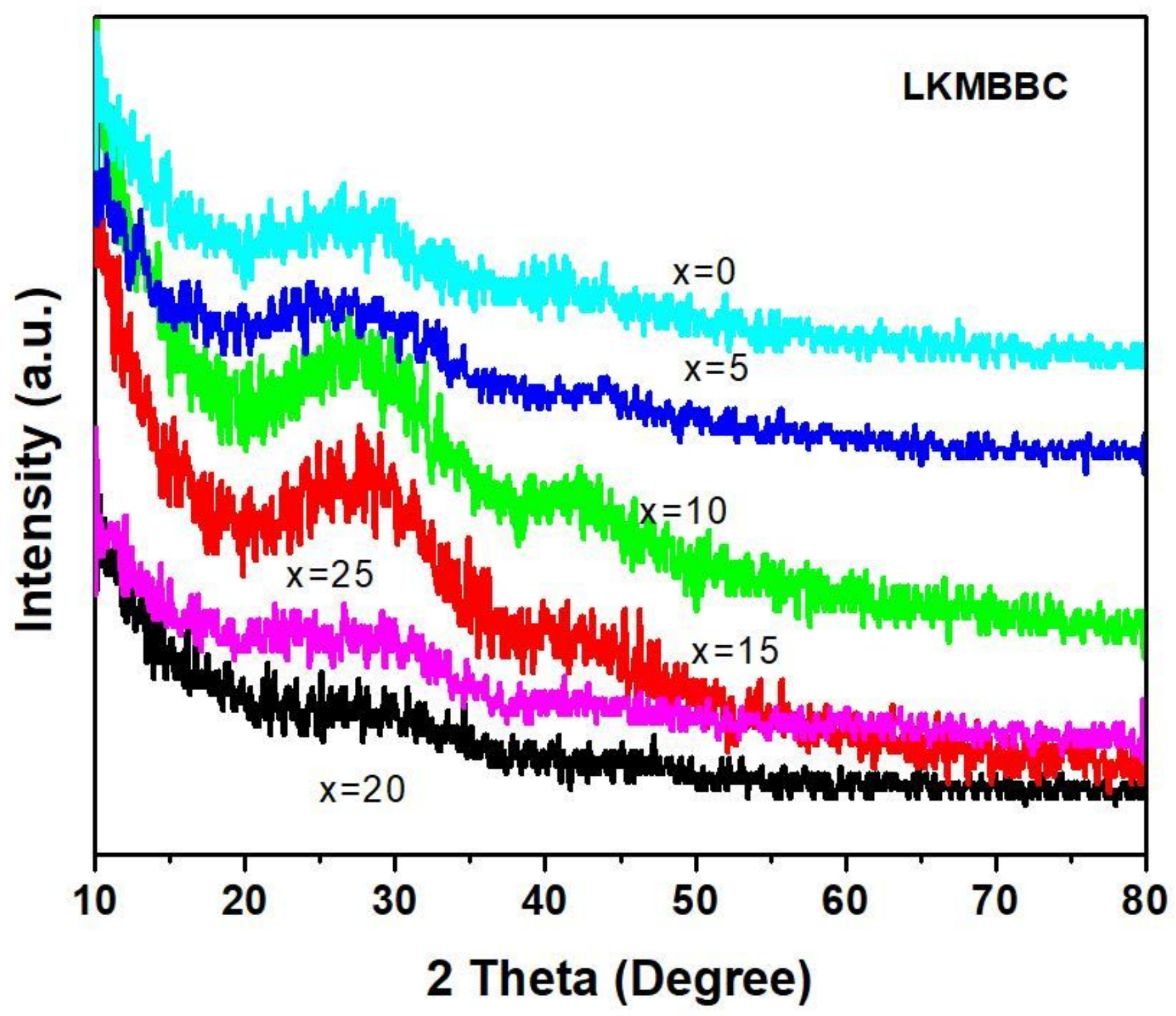

Figure 1

XRD patterns of KLMBC glasses. 


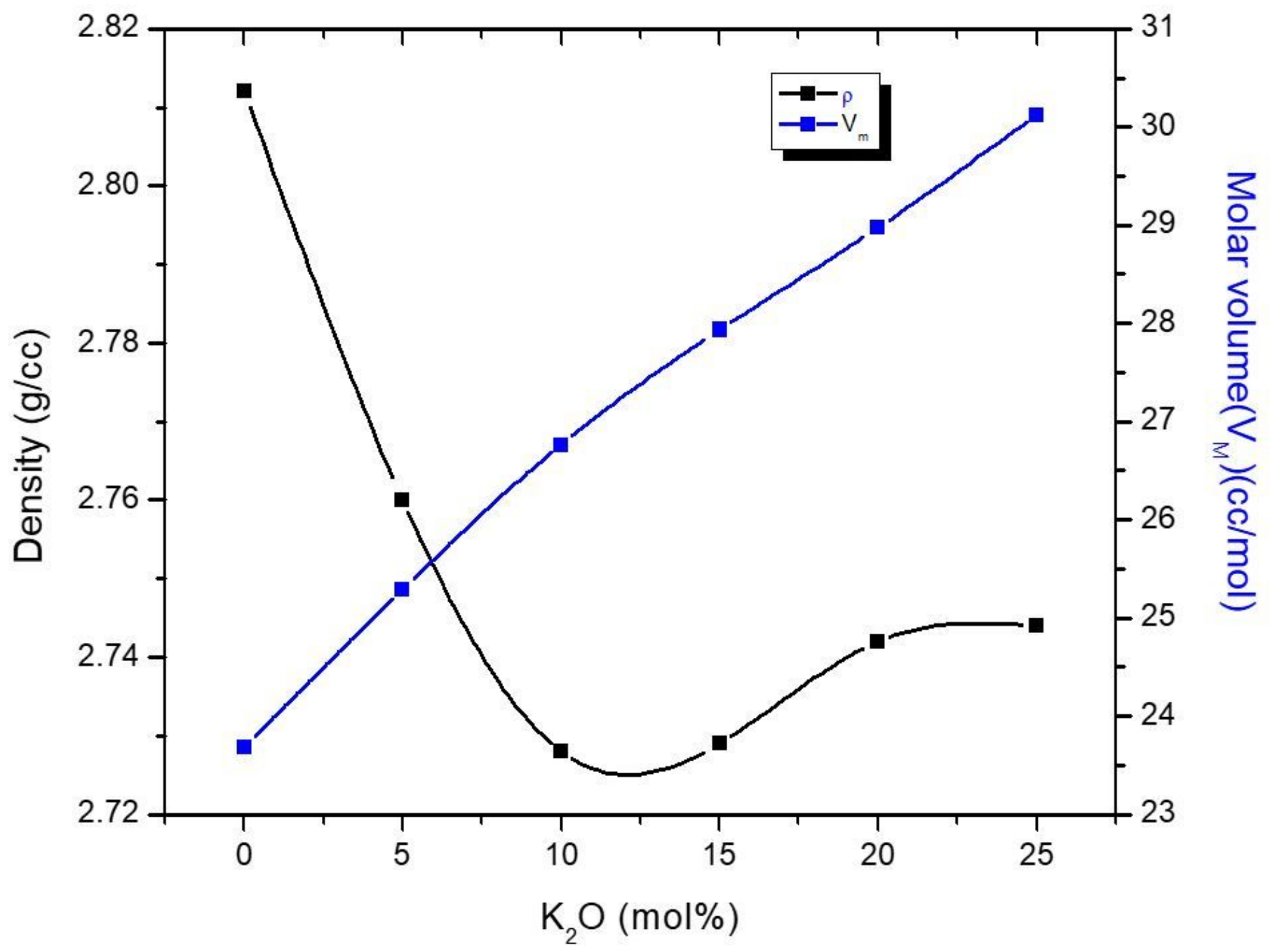

Figure 2

Plots the variation of density and molar volume as a function of $\mathrm{K} 2 \mathrm{O}$ content of present glasses. 


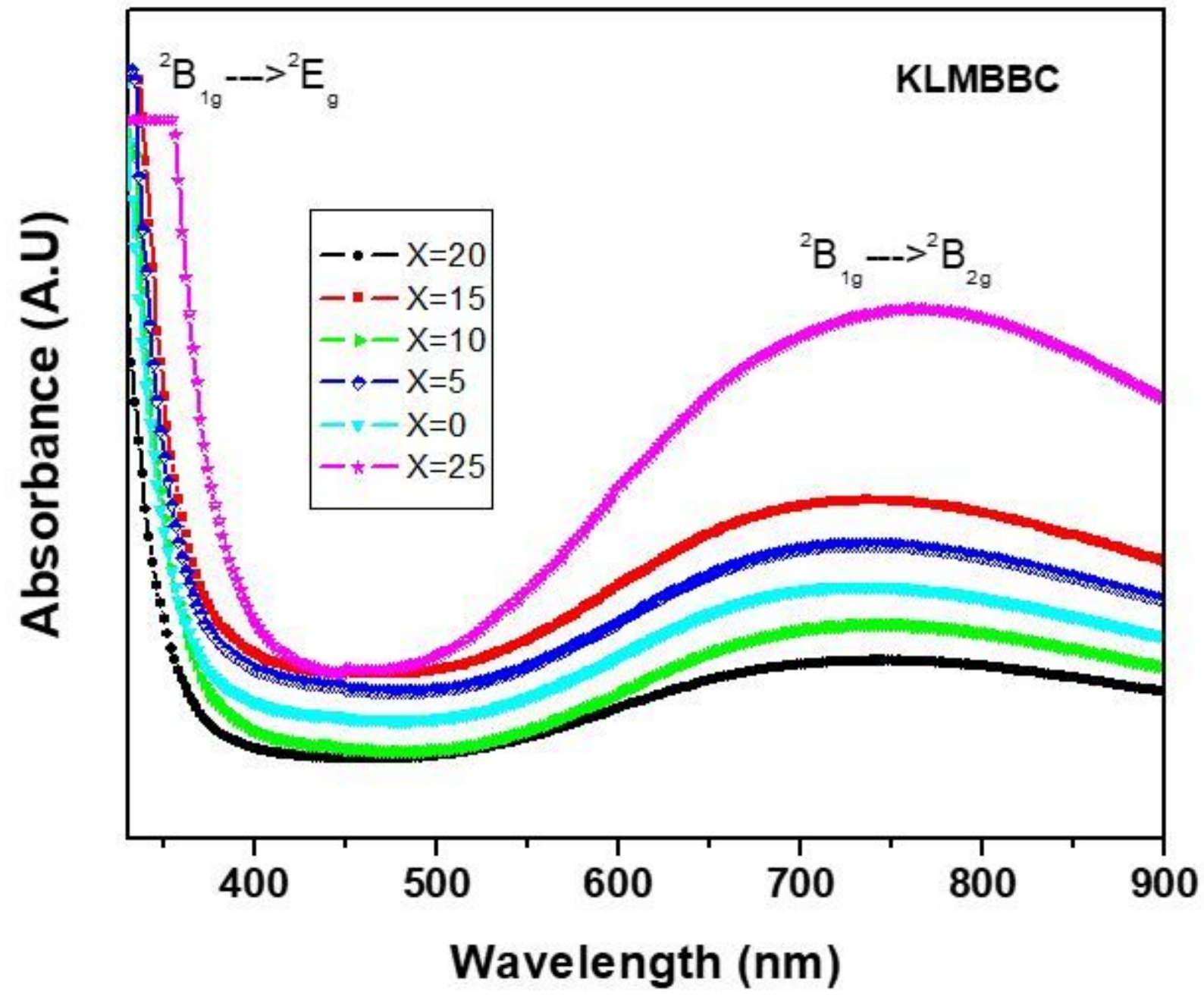

Figure 3

Optical absorption spectra of KLMBBC glasses. 


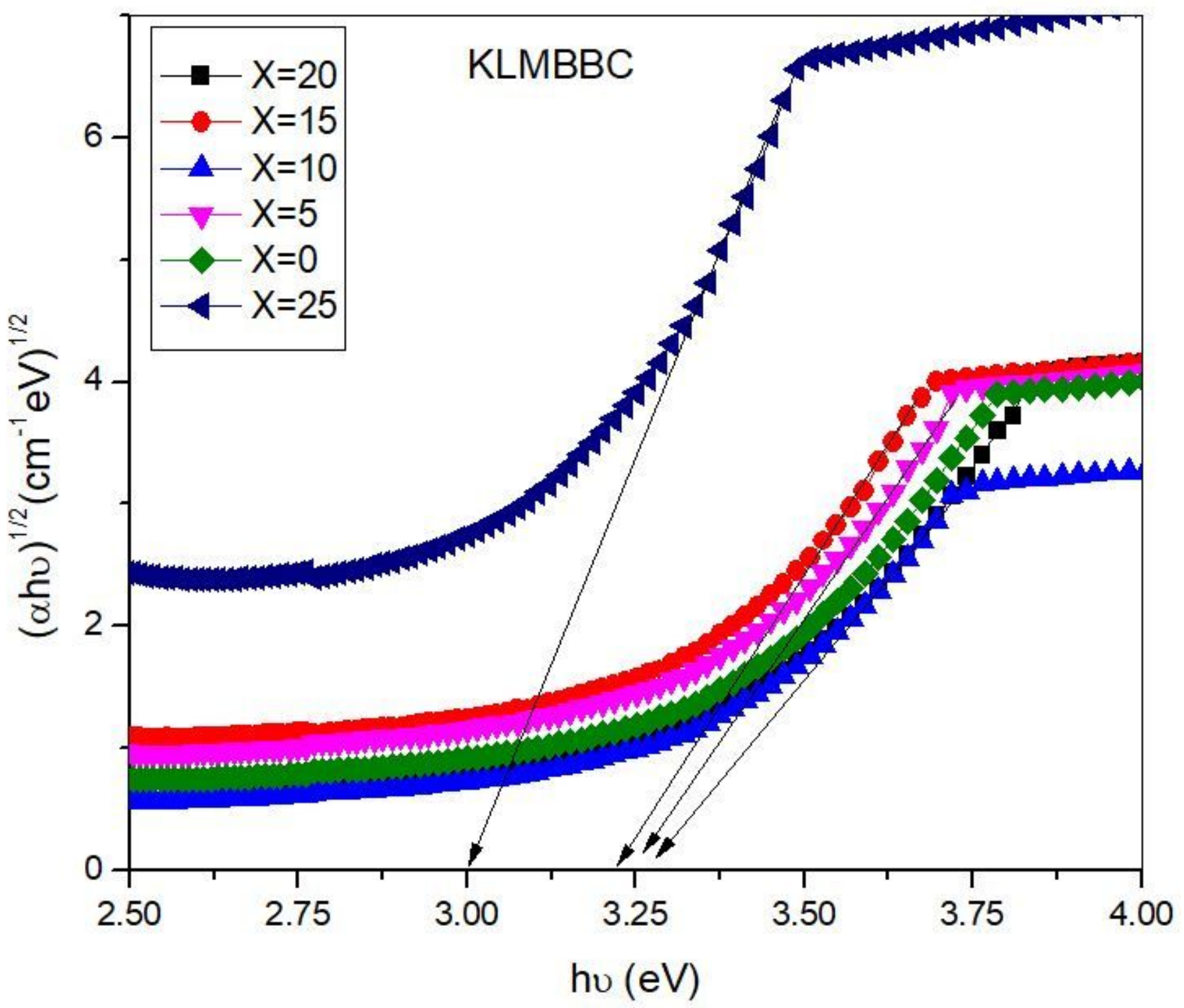

Figure 4

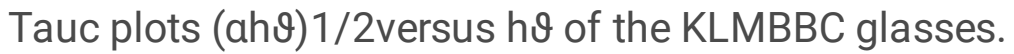




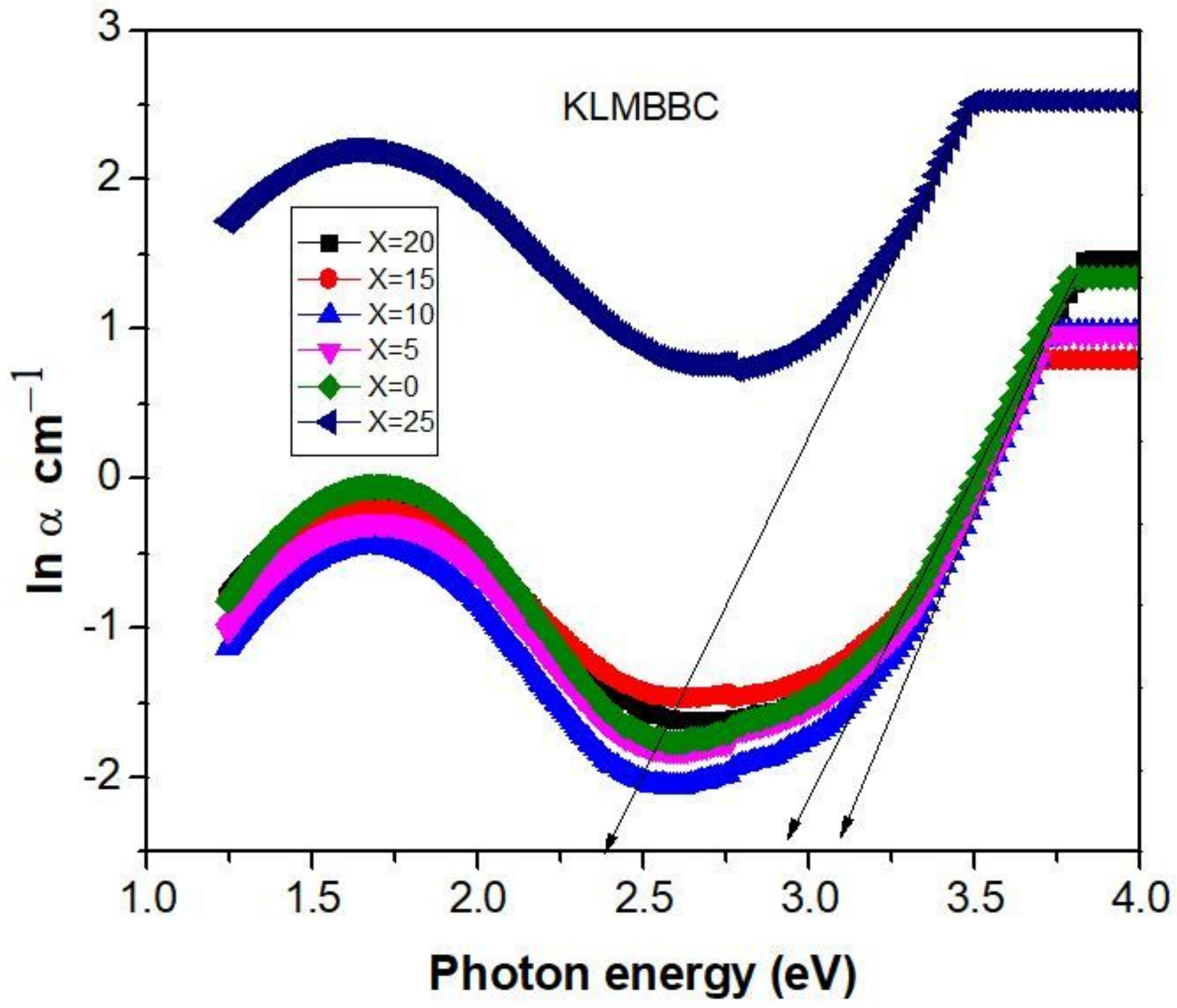

Figure 5

Urbach energy of the KLMBBC glass system. 


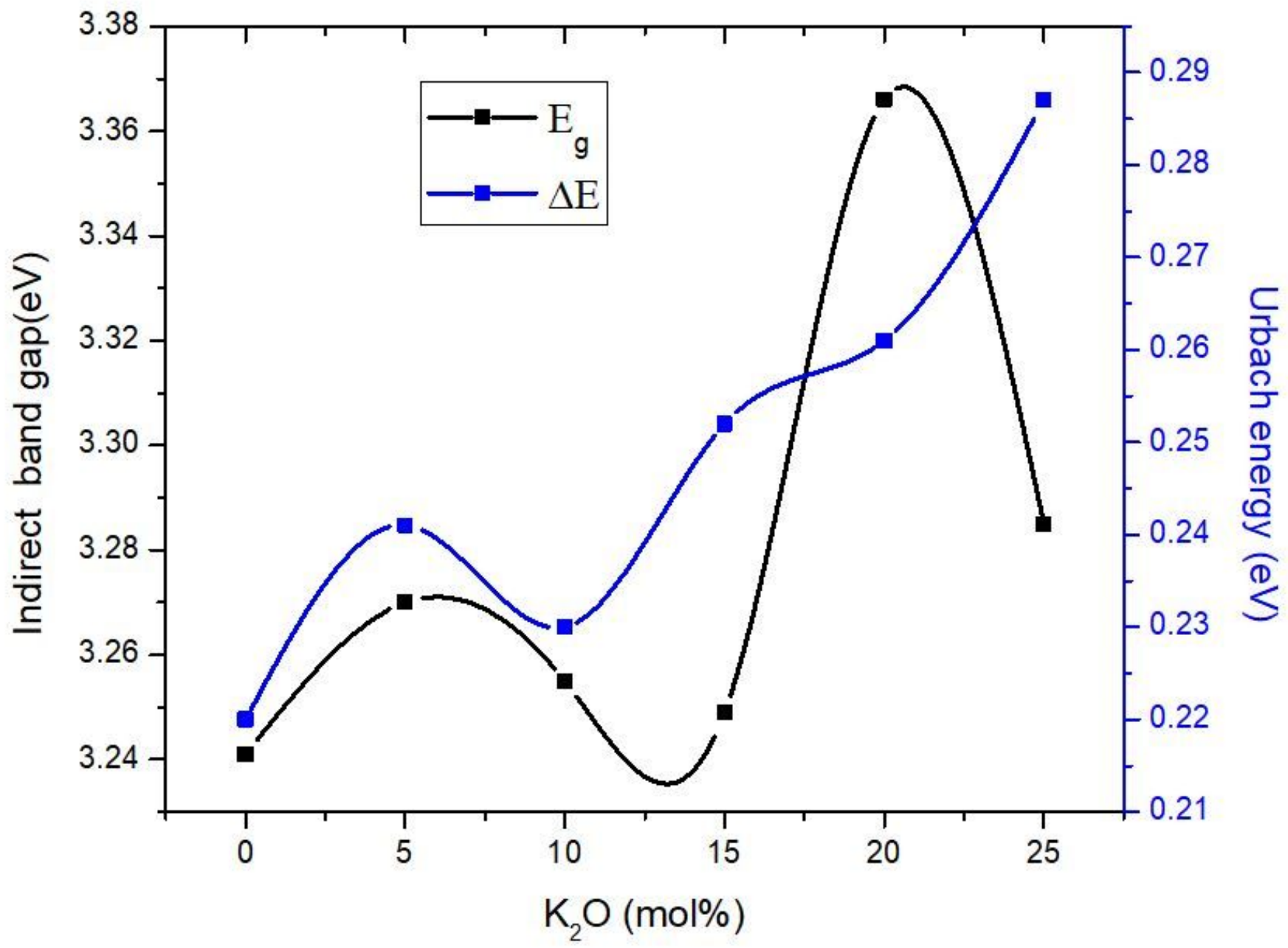

Figure 6

Variation of band gap and urbach energy values with K2O content. 


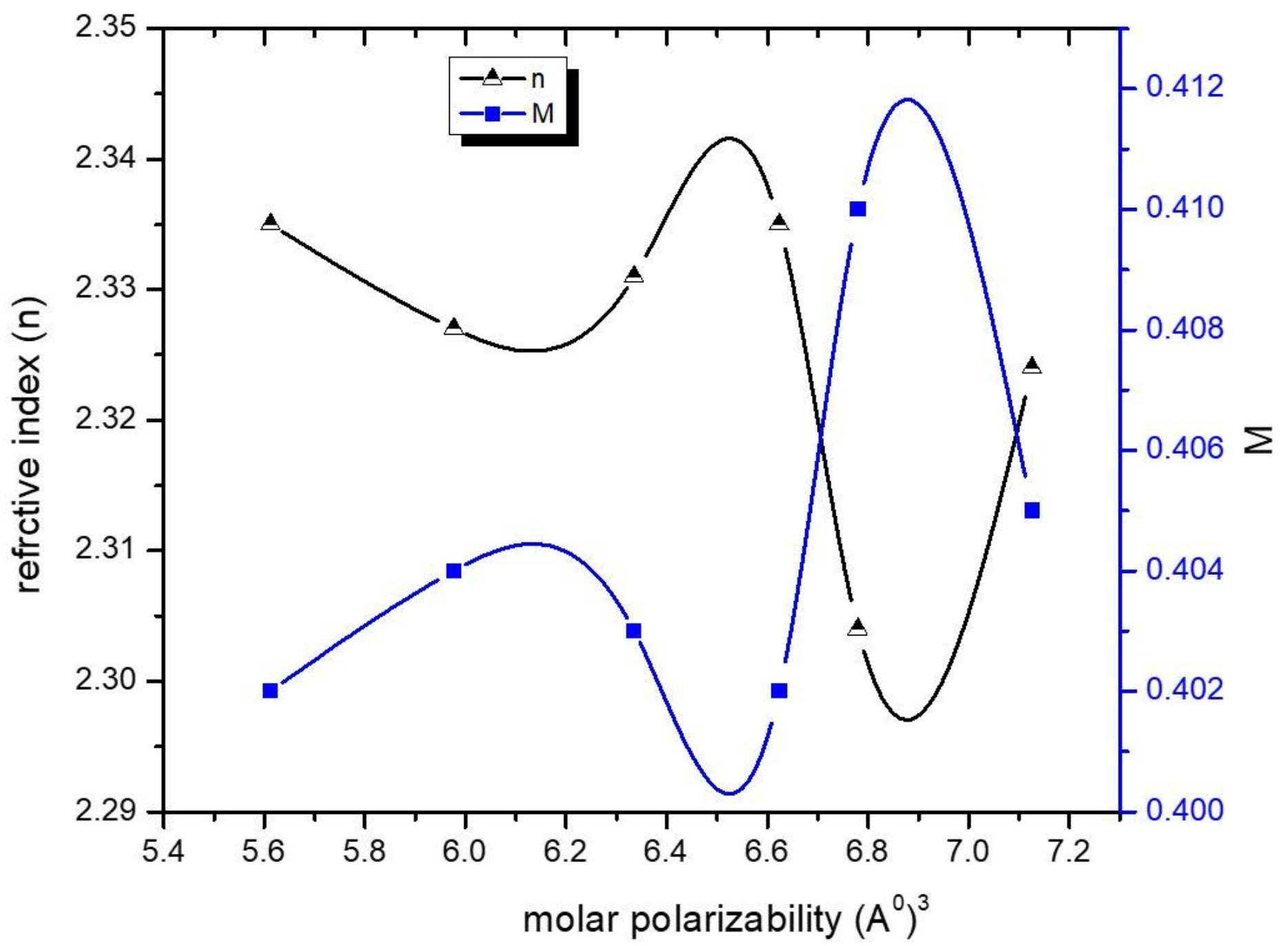

Figure 7

Variation of nand Mas a function of am parameter. 


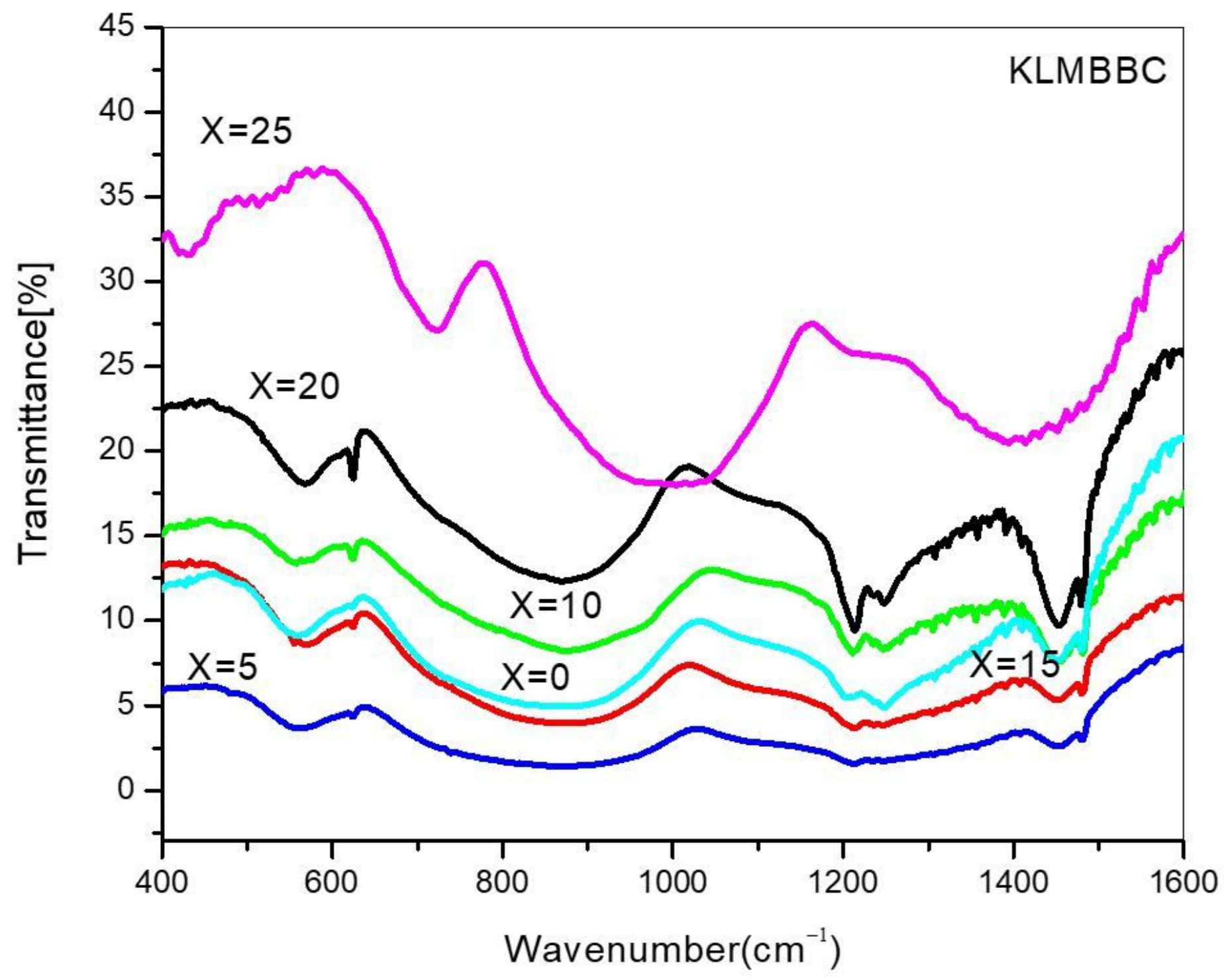

Figure 8

FTIR transition spectra of present glasses. 

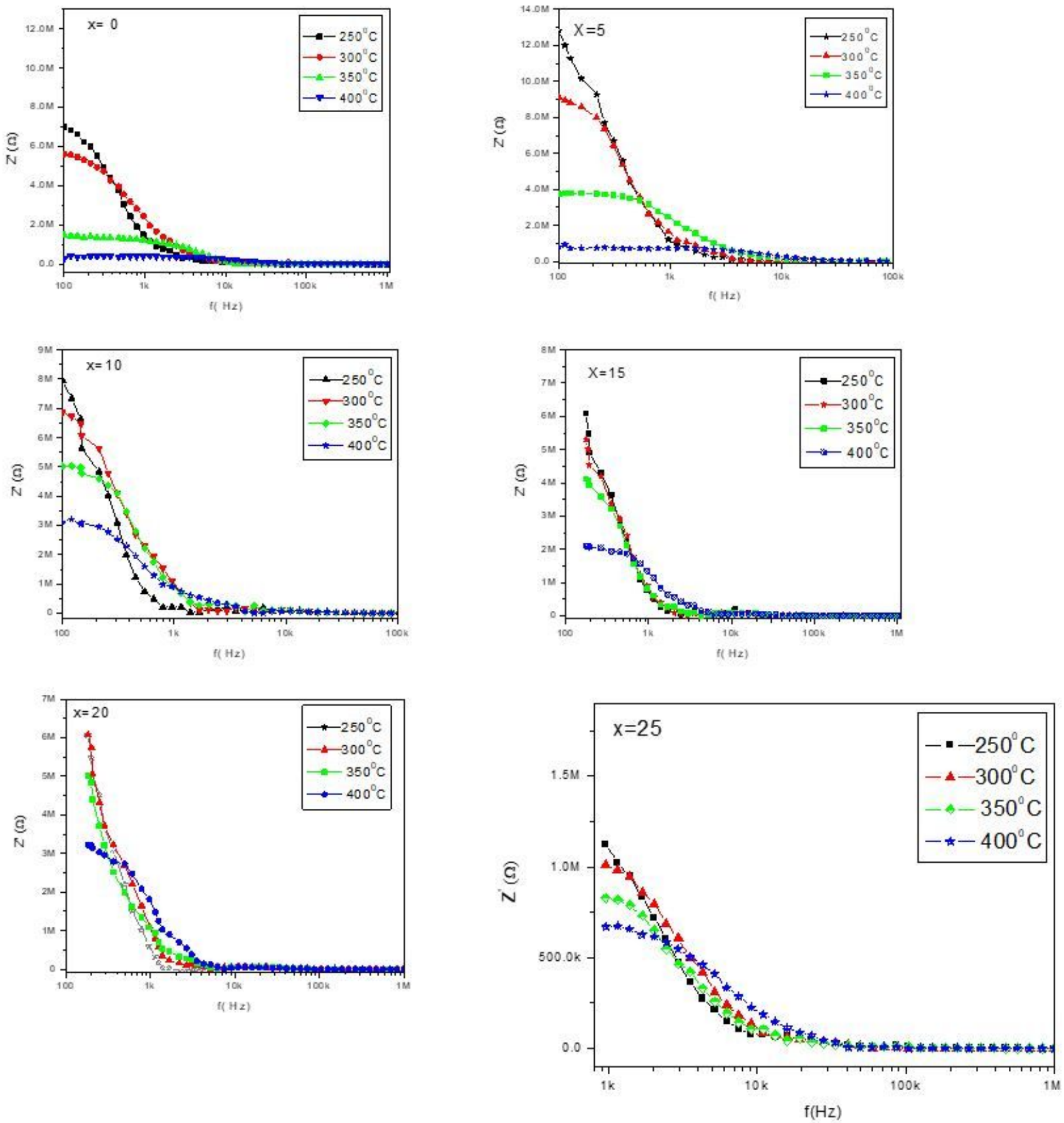

Figure 9

Variation in impedance $\left(z^{\prime}\right)$ with frequency at different temperatures for present glasses. 

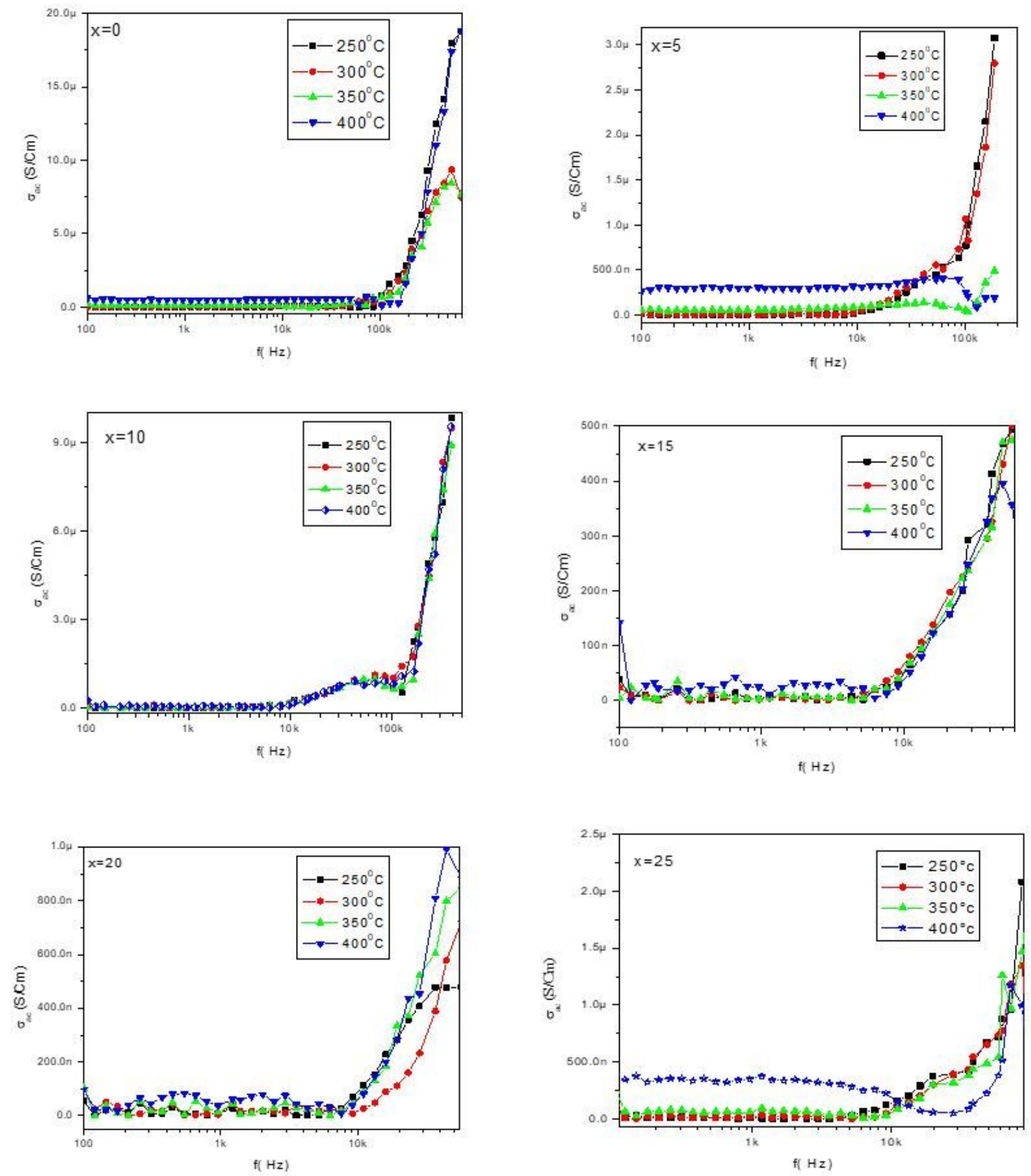

Figure 10

Variation of conductivity with frequency at different temperatures for present glasses. 


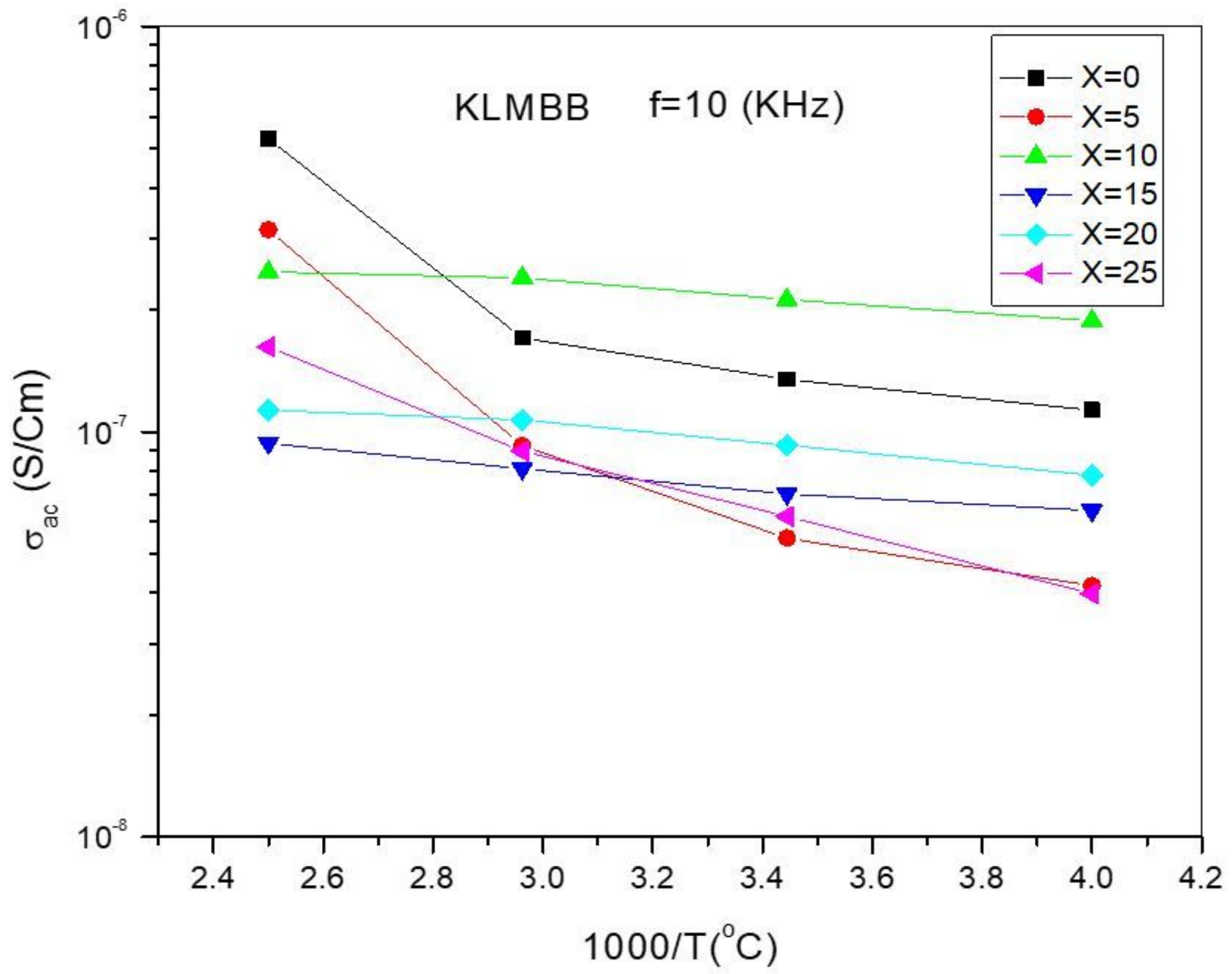

Figure 11

Variation of $\sigma a c$ versus $103 / \mathrm{T}$ at $10 \mathrm{k} \mathrm{Hz}$ frequency. 